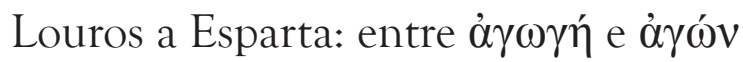

\author{
Maria Aparecida de Oliveira Silva*
}

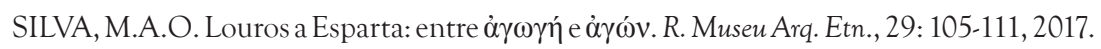

Resumo: $\mathrm{O}$ objetivo deste artigo é demonstrar a relação entre educação

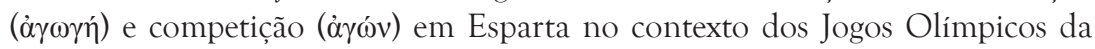
antiga Hélade.

Palavras-chave: Esparta; Jogos Olímpicos; Olimpiônicos, Licurgo; Agogé.

\section{Louros a Esparta}

O primeiro catálogo de vencedores dos Jogos Olímpicos foi elaborado por Hípias de Élis, por volta de 400 a.C., que lista desde os primeiros jogos realizados em 776 a.C. até os de sua época, cujo título escolhido foi

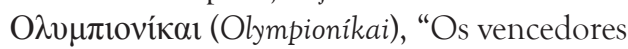
dos Jogos Olímpicos", ou os Olimpiônicos.

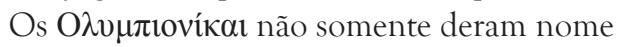
ao catálogo como também aos homens que se tornaram vitoriosos nas competições. A principal competição dos Jogos Olímpicos

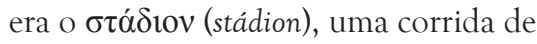
aproximadamente 200 metros. Em algumas cidades, os nomes dos vencedores do estádio se tornaram epônimos. Os vitoriosos deram seu nome ao ano e alcançavam grande influência social (Christesen 2012). Temos o célebre exemplo de Quione de Esparta: ele obteve sete vitórias nos Jogos Olímpicos no século VII a.C. e foi homenageado com estátuas em Olímpia e Esparta, além de outros monumentos no século V, sendo consagrado herói (Christesen 2010). Porém a grande marca simbólica dos Jogos Olímpicos era a coroa de louros que os

*Pesquisadora do Grupo Heródoto/Unifesp e membro do TAPHOS (Grupo de Pesquisas em Práticas Mortuárias no Mediterrâneo Antigo), MAE/USP. <madsilva@usp.br> vencedores das competições recebiam, e muitos louros olímpicos foram levados para Esparta. Há ainda o registro de vencedores em outras competições, mas não com a mesma regularidade com que se manteve a lista dos nomes dos vencedores do estádio.

Desde Hípias de Élis, os antigos helenos mantiveram a tradição de atualizar a lista dos vencedores, a ponto de os Jogos Olímpicos serem utilizados como referência cronológica para calendários e eventos históricos. E a tradição de atualização do catálogo se deu até 249 d.C. pelas mãos de Eusébio de Cesáreia em suas Crônicas, obra que foi preservada em grego e em armênio, em uma tradução que data de 450 d.C. e que se encontra no Codex Parisinus Graecus 2600 (Christesen \& Martirosova-Torlone 2006: 32). Embora a tradição de registrar os nomes dos vencedores no Catálogo dos Olimpiônicos tenha se mantido até o século III d.C., cobrindo 1.025 anos dos Jogos Olímpicos, em um registro que se perpetuou por sete séculos, os Jogos foram realizados até 393 d.C. (século IV), ano em que o imperador Teodósio I decretou sua extinção. E a cidade de Olímpia conhece o seu declínio no período romano tardio, quando é arrasada por invasões, depois por enchentes e terremotos, e sucumbe em ruínas até ser redescoberta em 1776, exatos 2.000 anos depois dos primeiros Jogos Olímpicos, pelo arqueólogo Richard Chandler. 
A leitura atenta do catálogo nos leva a perceber a predominância de nomes provenientes de Esparta e das suas regiões conquistadas, como a Lacônia e a Messênia. Depois do primeiro vencedor no estádio, Corebo de Eleia, em 776 a.C., o primeiro nome relacionado à Esparta é o de Ândroclo da Messênia, vencedor em 768 a.C., seguido de Ésquines, outro messênio, vencedor em 764 a.C. Há um intervalo até 752 a.C., quando há vitória consecutiva dos messênios Diócles, em 752 a.C., Antícles, em 748 a.C., Xenócles, em 744 a.C., Dotades, em 740 a.C., e Leocares em 736 a.C.

Após a vitória de Leocares, somente em 716 a.C. temos a vitória de Pitágoras da Lacônia e depois Ateradas em 700 a.C., e a partir desta existe um lapso temporal de vinte anos até a vitória de Tálpis em 680 a.C. Notamos que essas épocas em que nomes de messênios ou lacônios não figuram no Catálogo coincidem com as fortes guerras de conquista e manutenção da conquista da Messênia, período em que Esparta consuma a conquista da região da Lacedemônia e assume a sua liderança. A hegemonia espartana na Lacedemônia resultou em mudanças nas suas instituições por meio de novas leis, as que comumente são atribuídas a Licurgo. $\mathrm{O}$ primeiro a registrar essas mudanças foi Heródoto, como vemos no relato a seguir:

Pois, na época do reinado de Léon $^{1}$ e de Hegesicles ${ }^{2}$, em Esparta, os lacedemônios tiveram boa sorte nas demais guerras e somente contra os tegeatas sofreram um revés do destino. E ainda, no início, eram os que tinham as piores leis dentre quase todos os helenos e estavam isolados com relação a eles mesmos e aos estrangeiros. E mudaram para a boa legislação ${ }^{3}$ assim: quando Licurgo,

1 Rei espartano, filho de Euricrátides, que pertencia à casa dos Ágidas; reinou entre 590 e 560 a.C.

2 Rei espartano, filho de Arquidamo, que pertencia à casa dos Euripôntidas; reinou entre 575 e 550 a.C.

3 O termo usado é cv̉vopía (eunomia), que pode ser traduzido por boa ordem ou boa lei. A palavra eunomia possui uma riqueza semântica que nos leva a pensar em um homem notável dentre os cidadãos espartanos ${ }^{4}$, foi a Delfos para consultar o seu oráculo, quando entrou no vestíbulo, rapidamente a Pítia disse o seguinte:

Vieste, Licurgo, ao meu rico templo, caro a Zeus e a todos que habitam os palácios do

[Olimpo.

Estou em dúvida se profetizarei a ti como um deus [ou um homem; mas ainda suponho que és mais um deus, Licurgo.

Além disso, alguns dizem que, então, a Pítia lhe proferiu a ordem estabelecida que ainda hoje existe entre os cidadãos espartanos; e os próprios lacedemônios dizem que, enquanto Licurgo era tutor de Leobotes ${ }^{5}$, seu sobrinho, que reinava sobre os cidadãos espartanos, trouxe esses preceitos de Creta. (Clio, I, 65) .

Na cronologia de Heródoto, as leis licúrgicas teriam sido instituídas antes do advento dos Jogos

obediência à lei ou ao costume (ambos os conceitos estão contidos na palavra vó $\mu$ o / nomos) e ainda a posse de boas leis e de bons costumes.

4 O termo $\Sigma \pi \alpha \rho \tau$ tó $\tau\rceil \varsigma$ (spartiatēs), traduzido comumente como "esparciata", é o nome dado exclusivamente ao indivíduo cidadão espartano, distinguido por ter nascido em Esparta e ser filho de cidadãos espartanos. Em nossa

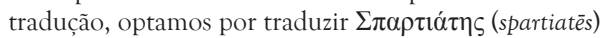
sempre por "cidadão espartano", em lugar de "esparciata".

5 Rei espartano da casa dos Ágidas; estima-se que tenha reinado entre 870 e 840 a.C.

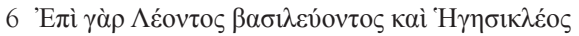

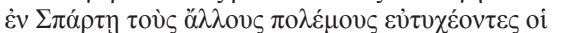

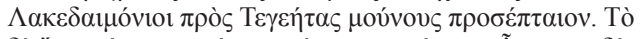

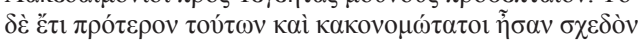

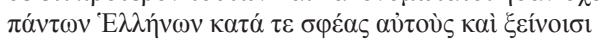

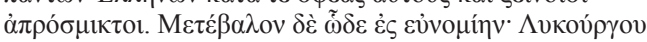

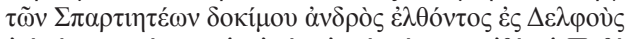

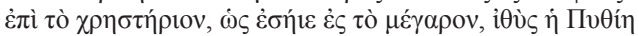

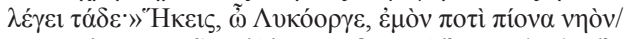

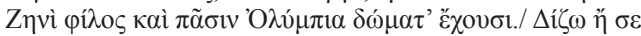

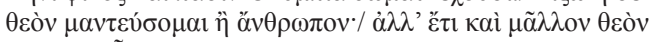

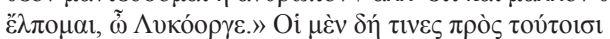

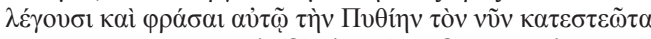

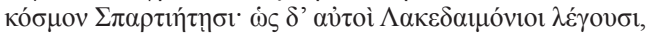
$\Lambda$

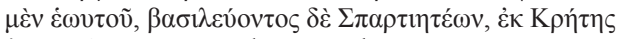
$\grave{\alpha} \gamma \alpha \gamma \varepsilon \dot{\varepsilon} \sigma \theta \alpha \imath \tau \alpha \tilde{\tau} \tau \alpha$. Tradução minha. 
Olímpicos, o que garante a Esparta a hegemonia nas vitórias da competição. As referências que temos do rei Leobotes nos remete ao século IX a.C., antes da datação que se convenciona utilizar para as reformas de Licurgo, entre os séculos VII e VI a.C., que seriam os séculos em que Esparta travou as guerras de conquista da Messênia. A conquista da Lacônia teria se dado entre os IX e VIII a.C., e aqui reside a maior dificuldade.

A questão principal é que não há evidências históricas fidedignas sobre quando ocorreu a guerra de conquista da Lacônia, e sobre as duas últimas duas guerras da Messênia temos os testemunhos dos versos de Tirteu e Álcman, nos que situam entre os séculos VII e VI a.C. Mas sabemos por meio de Pausânias (Descrição da Grécia, II, 3-5) que as primeiras batalhas entre espartanos e messênios ocorreram no segundo ano da nona olimpíada, em 743 a.C, e que a guerra da conquista da Messênia terminou no primeiro ano da décima quarta olimpíada, em 724 a.C. Convém notar que os messênios venceram sete vezes até 736 a.C., e depois dessa vitória, somente na Olimpíada de 428 a.C. que o nome de um messênio volta ao Catálogo dos Olimpiônicos.

Sobre o período arcaico espartano, Tucídides relata:

A Lacedemônia, depois da ocupação dos dórios que hoje a habitam, embora tenha sofrido as mais longas lutas civis que conhecemos, desde os tempos mais remotos, viveu sob o regime da lei e sempre esteve livre da tirania; até o fim desta guerra contam-se uns quatrocentos e poucos anos de observância do mesmo regime, donde lhes veios força para intervir nos assuntos das outras cidades.(História da Guerra do Peloponeso, I, XVIII) $)^{7}$.
O registro tucididiano não faz referência ao nome de Licurgo, porém nos indica que o regime espartano se tornou austero por conta da mudança nas leis no século VIII a.C., o que coincide com as informações de Pausânias. No entanto, as descobertas arqueológicas dos anos 1920 da Escola Britânica de Atenas trouxeram evidências de outras duas guerras contra a Messênia ${ }^{8}$, atestadas ainda nos versos de Tirteu e de Álcman. Portanto, na metade do século VIII a.C., quando Esparta dominou a Lacônia e a Messênia, a cidade se viu compelida a manter uma força militar permanente para defesa e manutenção dos territórios conquistados; é provável que as leis licúrgicas tenham sido implementadas após as conquistas da Lacônia e da Messênia, e que a preocupação com a defesa e a manutenção da sua cidade e das regiões conquistadas gerou a necessidade de uma nova ordem. Assim a segunda metade do século VII a.C. parece-nos a datação mais lógica para essa nova forma de governo instituída por Licurgo, mítico legislador espartano.

Segundo Plutarco, Licurgo decidiu implementar leis que mudassem o sistema político espartano por completo, visto que estava certo de que leis parciais não conteriam a insolência reinante entre os espartanos (Vida de Licurgo, V, 1-2). Então, o legislador espartano parte para Delfos, onde realiza sacrifícios a Apolo e consulta seu oráculo, inquirindo-o sobre quais leis deveria instituir em Esparta, quando a Pítia lhe responde que "ele era amigo dos deuses"

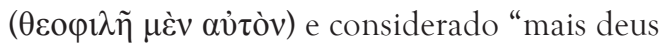
que homem” ( $\theta \varepsilon$ còv $\mu \tilde{\alpha} \lambda \lambda$ ov $\dddot{\eta}$ ö $v \theta \rho \omega \pi \mathrm{ov})$. Por isso, a Pítia lhe assegura que o deus lhe prometia uma boa legislação (Ev̉vopía) e que essa "seria muito mais poderosa que as demais

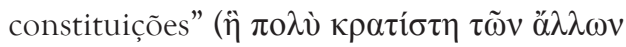

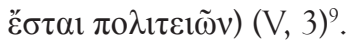

8 Sobre os primeiros resultados das escavações arqueológicas em Esparta, consultar Woodward \& Hobling 1925.

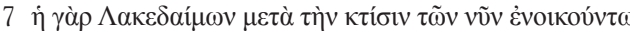

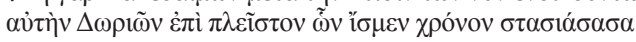

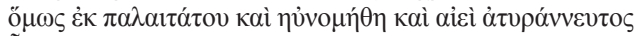

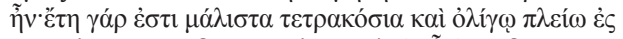

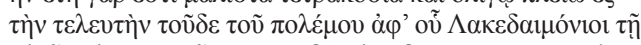

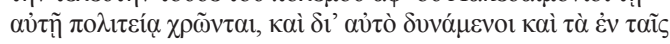

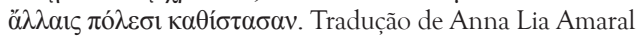
de Almeida Prado.
9 Observe a semelhança deste relato plutarquiano com o de Heródoto (Clio, I, 65). Para mais detalhes sobre a história espartana sob a perspectiva de Plutarco, consultar Silva 2006. 
Plutarco ressalta ainda que as leis de Licurgo deveriam permanecer inalteradas e lembra o episódio registrado nos versos de Tirteu:

\section{Após as ouvirem de Febo, do Pítio} [trouxeram para casa o oráculo do deus, estas conclusivas palavras: comandara assembleia os reis honrados pelos que se preocupam com Esparta, amável [deuses, [cidade, e os velhos gerontes, depois os homens do que obedecem às acertadas retras. [demo, (Vida de Licurgo, VI, 5) ${ }^{10}$.

Então, esse conjunto de leis proposto por Licurgo tinha como objetivo principal formar soldados-cidadãos com formação política e ética no sentido mais amplo. Tirteu, em seus versos, demonstra que, para Esparta, só existe

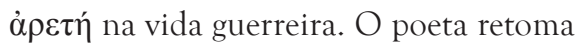
valores contidos já nos versos homéricos, como habilidades atléticas, porte gracioso, riqueza, poder, eloquência, glória e afirma que nenhuma delas tem valor na ausência da coragem guerreira: a $\alpha \rho \varepsilon \tau \eta ́$.

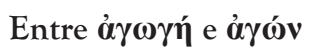

O substantivo $\dot{\alpha} \gamma \omega \gamma \eta \dot{~(a g o g e ́) ~ s i g n i f i c a ~}$ "direção", "condução", "educação",

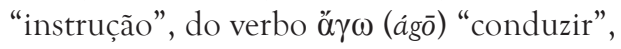
"guiar", "educar". Encontramos ainda com

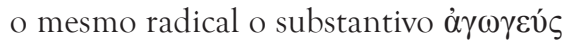
"condutor", que encontramos no substantivo composto $\pi \alpha \imath \delta \alpha \gamma o \gamma o ́ \varsigma$ que pode ser "o escravo que acompanha a criança à escola" ou o próprio "pedagogo", "mestre", visto ainda na palavra $\pi \alpha 1 \delta \alpha \gamma \omega \gamma i ́ \alpha$, que é a educação das crianças. Mas é interessante notar ainda que a palavra $\dot{\alpha} \gamma \omega \gamma \eta$ é mais analisada sob a perspectiva de "direção", "condução",

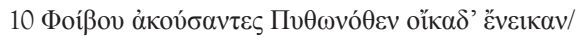

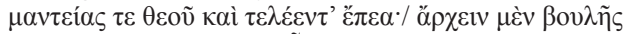

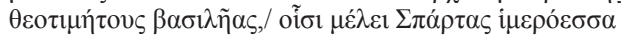

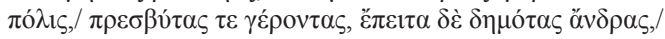

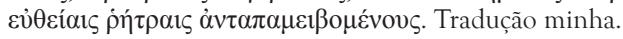

“educação", "instrução”, com o intuito de reforçar a austeridade da educação espartana.

Notamos sua presença no verbo $\sigma \tau \rho \alpha \tau \eta \gamma \varepsilon ́ \omega$ "conduzir um exército" e o seu substantivo

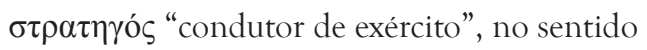
de guia, e o verbo ö $\gamma \omega$ em contexto de guerra passa a ter o sentido de "apoderar-se", aprisionar". Como exemplo, em Homero (Ilíada $\mathrm{V}, 484$ ), onde encontramos o uso dos infinitivos

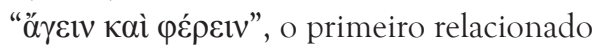
ao aprisionamento/apoderar-se de homens e animais, e o segundo ao transporte dos objetos. Assim, segundo Chantraine (1968), aos poucos o verbo ö $\gamma \omega$ adquire mais o significado de

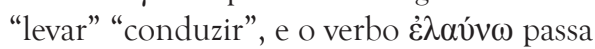
a assumir esse significado de "apoderar-se", 'pilhar', embora o sentido de "agarrar" e "apoderar-se" ainda seja visto em sua forma média, no contexto do casamento, na expressão

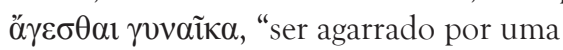
mulher" ou "casar-se".

$\mathrm{Na}$ sua origem, $\ddot{\alpha} \gamma \omega$ nos conduz a um contexto de coerção, onde a $\alpha \gamma \omega \gamma \eta ́$ espartana é vista como um elemento de austeridade. Sob essa mesma perspectiva militar, encontramos o substantivo å $\gamma \omega \dot{~}$ (agogón), que curiosamente em Homero também está associado à assembleia dos deuses ou reunião dos deuses, como assinala Chantraine (1968), na Ilíada (VII, 298):

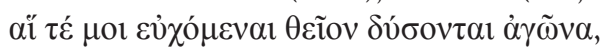
"as que oram por mim irão ao templo", no sentido de ir a um lugar onde há a reunião de estátuas dos deuses; por isso algumas traduções trazem "aos templos", como a de Carlos Alberto Nunes. Entendemos que está subentendido então o substantivo tò $\alpha$ $\gamma \alpha \lambda \mu \alpha$, "estátua". No entanto, o uso mais recorrente do substantivo àyóv em Homero está relacionado aos jogos, e por seu caráter de disputa, o termo foi associado aos combates militares e aos processos jurídicos. Portanto, percebemos que desde as suas primeiras aparições os vocábulos $\dot{\alpha} \gamma \omega \gamma \eta \dot{~ e ~}$ $\grave{\alpha} \gamma \omega ́ v$ transitam pelo campo semântico militar e esportivo, ou seja, das guerras e dos jogos.

Além desses significados, Chantraine (1968) aponta no verbete do substantivo $\dot{\alpha} \gamma \omega \gamma \eta \dot{a}$ a presença do redobro com o sentido de conduzir, no sentido de indicar a direção a ser tomada, sendo possivel traduzi-lo também 
como "modo de vida". Em Sopena, há também a sugestão de tradução para "conduta", "caráter". Essa amálgama de significados nos mostra claramente a coexistência de vocábulos semelhantes em contextos distintos, militar, esportivo e educativo, nos quais o $\alpha \gamma \omega \dot{v}$, a luta, ou a disputa, ocorre em três planos: o primeiro nos remete ao da superação do inimigo; no segundo há a necessidade de superação dos adversários nos jogos; e no terceiro há a superação de si mesmo, no sentido de ser virtuoso. É interessante perceber que os três nos indicam a necessidade de uma formação, ou seja, de uma educação anterior. O guerreiro tem de aprender a manusear suas armas, o desportista tem de aprender as técnicas de sua modalidade, e o virtuoso, sob a perspectiva do caráter, necessita de uma educação voltada para o desenvolvimento de suas qualidades pessoais.

Nesse sentido, a educação espartana revelase uma síntese dessas necessidades, a militar, a

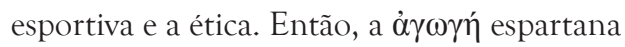
assume o significado de direção, visto que o cidadão espartano é guiado por essa agogé, que o direciona para o caminho das vitórias nas batalhas, nos jogos e no plano pessoal. Essa agogé, por sua natureza pedagógica, assume ainda a forma de uma prática cultural que confere ao substantivo o significado de modo de vida. Esparta surge assim como a cidade em que as leis e a educação atuam como transformadora do modo de vida de seus cidadãos. As diversas conquistas territoriais espartanas, por sua dimensão, respondem por essa organização social mais rígida e voltada para a defesa e a manutenção de seus territórios.

Os espartanos demonstram seu treinamento e sua força física no pancrácio, uma competição que envolvia luta e pugilato, e ainda mostram sua influência nos Jogos Olímpicos ao introduzir em 632 a.C. o pancrácio entre as modalidades competitivas (Crowther 1997: 199). A despeito dos acertos e erros das leis licúrgicas, o fato é que Esparta destacou-se sobremaneira nas competições atléticas dos Jogos Olímpicos até o período clássico, como pode ser visto no Catálogo dos Olimpiônicos, recebendo muitos louros. Sobre isso temos ainda o testemunho de Aristóteles:
E além disso, sabemos que os próprios lacônios, enquanto eles se mantiveram afeitos à atividades penosas, superam os demais, e agora foram deixados para trás nas competições gímnicas e nas guerras pelos outros; pois não se distinguiam por exercitar seus filhos desse modo, mas por eles somente se exercitarem diante dos que não se exercitam. (A Política, 1328b, 19-25) ${ }^{11}$.

No entanto, percebemos que o filósofo relativiza a visão de uma Esparta rígida, de cidadãos sempre se exercitando por modos mais penosos, a fim de se tornarem soldados extraordinários, tal como Leônidas e os 300. Aristóteles coloca em questão a preparação militar dos seus vizinhos, levando-nos a pensar que Esparta estava preparada diante de despreparados e que sua supremacia se desfez não apenas por declínio das suas leis e da sua educação, mas também porque os povos vizinhos se prepararam para enfrentá-los.

\section{Conclusões}

Convém anotar que as mulheres não participavam dos Jogos Olímpicos até a primeira metade do período clássico (Mouratidis 1984), quando temos o relato de Plutarco sobre Cinisca, filha do rei Arquidamo II de Esparta, que venceu na corrida de cavalos nos Jogos Olímpicos (Vida de Agesilau, 1-1). E a presença dos meninos nesse regime de exercícios intensos e penosos é percebida quando os espartanos introduzem o pancrácio como modalidade olímpica e trazem meninos como competidores em 632 a.C. (Crowther 1989: 206).

A virtude guerreira exaltada pela educação espartana revela o caráter agônico de sua

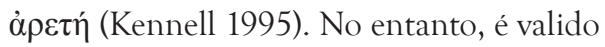
ressaltar que esse universo virtuoso está restrito à sua antiga aristocracia, que está destinada a seguir os preceitos educacionais exclusivos

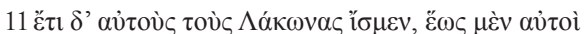

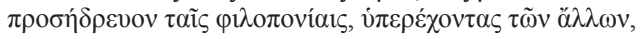

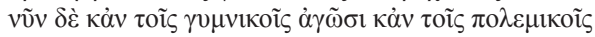

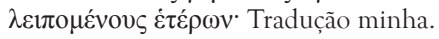


aos cidadãos espartanos, práticas culturais que se refletem na hegemonia espartana nos Jogos Olímpicos da era arcaica ${ }^{12}$. Como vimos, o termo ảyóv (agốn) aparece em Homero relacionado a guerra, mas também aos jogos, atividades que o poeta associa aos heróis de seu tempo, o que traz ao imaginário do povo espartano a ideia de continuidade de práticas inerentes aos seus antigos heróis ${ }^{13}$.

Assim podemos depreender que $\alpha \hat{\gamma} \omega \dot{v}$ (agốn), a luta ou a disputa, aflora no povo espartano a imagem de um povo heroico, de uma coragem que se estende às competições atléticas.

SILVA, M.A.O. Laurels to Sparta: between $\dot{\alpha} \gamma \omega \gamma \eta \dot{~ a n d ~} \alpha \gamma \omega \dot{v}$. R. Museu Arq. Etn., 29: 105-111, 2017.

Abstract: The aim of this paper is to demonstrate the relationship between education $(\dot{\alpha} \gamma \omega \gamma \eta \dot{)})$ and competition $(\dot{\alpha} \gamma \omega \dot{\omega})$ in Sparta in the context of the Olympic Games of ancient Hellas.

Keywords: Sparta; Olympic Games; Olympioníkai; Lycurgus; Agoge.

\section{Referências bibliográficas}

Aristóteles. 2018. A política. Tradução, introdução e notas de Maria Aparecida de Oliveira Silva. Edipro, São Paulo, 2018.

Barringer, J.M. 2005. The temple of Zeus at Olympia, heroes, and athletes. Hesperia 74(2): 211-241.

Chantraine, P. 1968. Dicitionnaire étymologique de la langue grecque: histoires de mots. Klincksieck, Paris. 2 v.

Christesen, P. 2010. Kings playing politics: the heroization of Chionis of Sparta. Zeitschrift für Alte Geschichte 59 (1): 26-73.

Christesen, P. 2012. Athletics and social order in Sparta in the Classical period. Classical Antiquity 31 (2): 193-255.

Christesen, P.; Martirosova-Torlone, Z. 2006. The Olympic victor list of Eusebius: background, text, and translation. Traditio 61: 31-93.

12 Para mais detalhes, consultar Crowther (1985a; 1985b).
Crowther, N.B. 1985a. Studies in Greek athletics: part I. The Classical World 78: 497-558.

Crowther, N.B. 1985b. Studies in Greek athletics: part II. The Classical World 79: 73-135.

Crowther, N.B. 1989. Boys victors at Olympia. L’Antiquité Classique 58: 206-210.

Crowther, N.B. 1997. Spartan Olympic boxing champion. L'Antiquité Classique 59: 198-202.

Heródoto. 2015. Livro I: Clio. Tradução, introdução e notas de Maria Aparecida de Oliveira Silva. Edipro, São Paulo.

Homer. 1999. The Iliad. Translated by Augustus T. Murray and revised by William F. Wyatt. $2^{\text {nd }}$ ed. Harvard University, Cambridge. 2 v.

Kennell, N.M. 1995. The gymnasium of virtue: education and culture in Ancient Sparta. University of North Carolina, Chapel Hill.

13 Sobre os cultos de heróis e atletas há o interessante artigo de Barringer (2005). 
Mouratidis, J. 1984. Heracles at Olympia and the exclusion of women from the Ancient Olympic Games. Journal of Sport History 11 (3): 41-55.

Pausanias. 1997. Description of Greece. v. 2. Translated by Willian H. S. Jones. Harvard University, Cambridge. books 3-4. $6 \mathrm{v}$.

Plutarch. 2005. Life of Theseus. Lives. v. 1. Translated by Bernadotte Perrin. Harvard University, Cambridge.
Silva, M.A.O. 2006. Plutarco historiador: análise das biografias espartanas. Edusp, São Paulo.

Tucídides. 2008. História da Guerra do Peloponeso: livro 1. Tradução e apresentação de Anna Lia de Almeida Prado. Texto grego estabelecido por Jacqueline de Romilly. 2a ed. Martins Fontes, São Paulo.

Woodward, A.M.; Hobling, M.B. 1925. Excavations at Sparta, 1924-25. Annual of the British School at Athens 26: 116-310. 